\title{
EXPLORANDO O CONCEITO DE IDEOLOGIA: UMA TENTATIVA DE APROXIMAÇÃO ENTRE HERMENÊUTICA DE PROFUNDIDADE E HISTÓRIA ORAL
}

\section{- KÁTIA GUERCHI GONZALES}

Universidade Estadual do Mato Grosso do Sul

\section{ANTÔNIO VICENTE MARAFIOTI GARNICA}

Universidade Estadual Paulista

A intenção deste texto é considerar as possibilidades e potencialidades de articular dois referenciais teórico-metodológicos específicos - a Hermenêutica de Profundidade (HP) e a História Oral (HO), focalizando particularmente o conceito de ideologia. A HP, que se volta à análise de formas simbólicas das mais variadas, tem sido mobilizada mais frequentemente em pesquisas relacionadas à análise de materiais escritos, como livros didáticos. Entretanto, o objetivo deste artigo é apresentar considerações sobre como - sob quais parâmetros - a HP poderia ser mobilizada para a análise das textualizações/ narrativas criadas segundo a metodologia da História Oral. Concluindo o texto, apresentamos um exercício de mobilização da HP, em que se ressalta o conceito de ideologia, realizado tendo em vista atribuir sentido às Licenciaturas de Ciências - Habilitação em Matemática, ocorridas em regime parcelado, no Estado do Mato Grosso do Sul.

Palavras-chave: Hermenêutica de profundidade. História oral. Educação matemática. Ideologia.

\section{ABSTRACT EXPLORING THE CONCEPT OF IDEOLOGY: AN ATTEMPT TO APPROXIMATE BETWEEN DEPTH HERMENEUTICS AND ORAL HISTORY}

The intention of this text is to consider the possibilities and potential of articulating two specific theoretical and methodological references - Depth Hermeneutics (DH) and Oral History $(\mathrm{OH})$, focusing particularly on the concept of ideology. Depth Hermeneutics, which aims to the analysis of several distinguished symbolic forms, has been mobilized more frequently in research related to the analysis of written materials such as textbooks. However, the objective of this article is 
to present considerations about how - under what parameters - $\mathrm{DH}$ could be used to analyze textualizations/narratives created according to Oral History methodology. As a conclusion, we present an exercise in the mobilization of $\mathrm{DH}$, emphasizing the concept of ideology, carried out aiming to give meaning to the Licentiates of Sciences Qualification in Mathematics, occurring in a piecemeal regime in the state of Mato Grosso do Sul.

Keywords: Depth Hermeneutics. Oral History. Mathematical Education. Ideology.

\section{RESUMEN EXPLORANDO EL CONCEPTO DE IDEOLOGÍA: UN INTENTO DE APROXIMACIÓN ENTRE HERMENÉUTICA DE PROFUNDIDAD E HISTORIA ORAL}

La intención de este texto es considerar las posibilidades y potencialidades de articular dos referenciales teórico-metodológicos específicos -la Hermenéutica de Profundidad (HP) y la Historia Oral (HO), enfocando particularmente el concepto de ideología. La HP, que se vuelve al análisis de formas simbólicas de las más variadas, ha sido movilizada más frecuentemente en investigaciones relacionadas al análisis de materiales escritos, como libros didácticos. Sin embargo, el objetivo de este artículo es presentar consideraciones sobre cómo - bajo qué parámetros - la HP podría ser movilizada para el análisis de las texturas / narrativas creadas según la metodología de la Historia Oral. Concluyendo el texto, presentamos un ejercicio de la movilización de HP, resaltando el concepto de ideología, realizado para dar sentido a las Licenciaturas de Ciencias - Habilitación en Matemáticas, ocurridas en régimen parcelado en el estado de Mato Grosso do Sul.

Palabras clave: Hermenéutica de Profundidad. Historia Oral. Educación Matemática. Ideología.

\section{Introdução}

Este artigo é recorte de uma pesquisa de doutorado intitulada Formar professores que ensinam matemática: uma história do movimento das licenciaturas parceladas no Mato Grosso do Sul, que teve como tema as chamadas Licenciaturas Parceladas, ${ }^{1}$ desde o momento de

1 As Licenciaturas Parceladas são uma modalidade emergencial de formação docente, em nivel superior, oferecida por polos de Universidades oficiais. Elas são desenvolvidas parceladamente, em épocas sua implantação - que ocorreu no então Mato

específicas do ano, pois sua intenção é habilitar em Licenciatura professores leigos em efetivo exercício do magistério. 0 estudo que apoia a elaboração deste artigo diz respeito a dois projetos dessa natureza: um deles relativo a uma Licenciatura Curta em Ciências, criada na década de 1970 e desenvolvida no então Mato Grosso Uno (assim chamado dado tratar-se de época anterior à divisão do estado, que ocorreu em 1979) , e uma Licenciatura em Ciências - habilitação em Matemática, da década de 1990, no Mato Grosso do Sul. Este artigo, mais especificamente, refere-se à Licenciatura Parcelada da década de 1990. 
Grosso Uno - até sua extinção, quando já havia sido criado o Estado de Mato Grosso do Sul. Mobilizamos, para isso, documentos escritos e orais, na tentativa de criar uma arquitetura analítica que nos permitisse elaborar uma versão sobre esses cursos não-convencionais de formação voltados a professores leigos que ensinam/ensinavam Matemática. Sob essa ótica, duas frentes distintas foram focalizadas: houve uma Licenciatura Parcelada de Curta Duração de Ciências (vigente na década de 1970) e uma Licenciatura em Regime Parcelado de Ciências - habilitação em Matemática (vigente na década de 1990).

Dois referenciais teóricos-metodológicos apoiaram o desenvolvimento desse estudo. A História Oral nos permitiu criar fontes a partir da oralidade, constituindo, assim, uma trama narrativa a partir de memórias de vários colaboradores, que em nosso caso foram professores, administradores e ex-alunos desses cursos, totalizando 14 entrevistas. ${ }^{2}$ Desse modo, as narrativas constituídas segundo as disposições da História Oral (HO), juntamente com outros recursos documentais, permitiram uma análise, fundada num diálogo entre fontes de diversas naturezas, da qual resultaram algumas compreensões sobre o nosso objeto de estudo. A Hermenêutica de Profundidade, proposta por John Thompson (2011), sociólogo inglês, também foi mobilizada como perspectiva teórico-metodológica, o que possibilitou tecer sentidos para as Licenciaturas parceladas tomadas, então, como forma simbólica.

Este texto é um recorte dos nossos trabalhos relativos às ideologias, que cercam as Licenciaturas de Ciências - Habilitação em

2 As entrevistas da nossa pesquisa foram concedidas por Carlos Henrique Patusco, Massao Uetanabaro, Sérgio Delvízio Freire, Luiz Carlos Pais, José Luiz Magalhães de Freitas, Sidnei Azevedo de Souza, Edmir Ribeiro Terra, Celso Correia de Souza, Antônio Lino Rodrigues de Sá, Maria Luiza da Silva Correa, Antônio Enes Nonato, Gilberto Luiz Alves e Antônio Carlos do Nascimento Osório.
Matemática desenvolvidas em regime parcelado no Mato Grosso do Sul. Mas nosso foco é, também, apresentar os referenciais metodológicos mobilizados no trabalho e, ainda que de forma breve, esboçar aspectos do estudo por nós implementado para fundamentar o uso da HP de John Thompson como ferramenta teórica para análise das narrativas criadas a partir do uso da HO. Pode-se dizer que a história das tentativas de vincular essas duas abordagens teórico-metodológicas é bastante recente, e implica um certo ineditismo, já que a HP tem sido mais usualmente mobilizada para analisar formas simbólicas outras que não as narrativas geradas a partir de uma perspectiva específica, criadas a partir da oralidade.

\section{Um pouco sobre a Hermenêutica de Profundidade}

Orientado principalmente pelas obras de Paul Ricouer (1987, 1988), Thompson (2011) apresenta uma perspectiva teórica-metodológica denominada Hermenêutica de Profundidade, que visa à interpretação de formas simbólicas. Formas Simbólicas são elaborações humanas que possuem uma intenção, estão presentes em determinados tempos e espaços e fazem funcionar relações assimétricas de poder. Segundo John Thompson, há três fases principais da HP que ocorrem simultaneamente, sendo mutuamente interdependentes e complementares: a análise socio-histórica, a análise formal e a interpretação/reinterpretação.

A análise socio-histórica visa reconstruir, tanto quanto possivel, as condições sociais de produção, circulação e recepção das formas simbólicas, que, afinal, não se constituem num vácuo. Procura-se, então, descrever situações no espaço e no tempo (analisar ambientes em que as formas simbólicas se constituíram, se propagaram e foram apropriadas por sujeitos em locais e tempos específicos); enfocar cam- 
pos de interação (analisar um conjunto de trajetórias e posições das relações entre os sujeitos), as instituições sociais (registrar o conjunto de regras, recursos e relações que constituem e sustentam, temporal e espacialmente, e as formas simbólicas, observando as atitudes e práticas dos sujeitos que agem nelas, por elas e em favor delas); e a estrutura social (identificar as assimetrias e as diferenças que definem os campos de interação e também as instituições sociais). Outro elemento fundamental ao estudo das formas simbólicas são os meios técnicos (elementos materiais utilizados para a produção e a transmissão dessas formas), que determinam algumas de suas características, como, por exemplo, seu grau de reprodutibilidade. Como os meios técnicos estão inseridos em um contexto, a investigação deles tem também a finalidade de apreender contextos sociais mais amplos. Além dessas tarefas da primeira fase da $\mathrm{HP}$, é essencial que se abordem as maneiras e as estratégias da ideologia presente no contexto social, que sustentam e distribuem o poder, os recursos e as oportunidades, como também a sustentação de assimetrias, injustiças e desigualdades que se materializam em dominação e na construção de campos diferenciados e socialmente estruturados.

A análise formal ou discursiva parte do pressuposto de que objetos e expressões que circulam nos campos sociais são construções complexas que apresentam uma estrutura articulada. Dessa maneira, visa-se analisar a organização interna, as características, os padrões, as relações presentes nas formas simbólicas. Tal fase é de suma importância, já que focaliza a perspectiva da estrutura interna do objeto analisado, de modo que o pesquisador pode utilizar o padrão formal de análise ${ }^{3}$ que

3 Thompson (2011) apresenta algumas possibilidades de análise, resumidas por Oliveira, Andrade e Silva (2013):

[...] uma análise semiótica cuidaria de analisar as características estruturais internas de uma forma simbólica/ julgar mais adequado ao tipo de forma simbólica analisado. Esse momento - que implica, de certo modo, desconstruir a forma simbólica, numa busca aos seus elementos internos constitutivos - é importante, mas perde o sentido se feito isoladamente das outras fases. Assim, é essencial que o tipo de método de que lançaremos mão seja compativel com a forma simbólica e nos ajude a desenvolver as considerações relativas a essa fase. Devemos sempre relacionar a análise de uma forma/ obra com as condições de sua produção, circulação, recepção ou, em outras palavras, com o seu contexto socio-histórico, e também com a fase de interpretação (reinterpretação).

A fase da interpretação/reinterpretação é determinada por uma construção criativa, um movimento novo de pensamento que, segundo Thompson (2011), se dá a partir da análise socio-histórica e da análise formal. Ela, porém, se diferencia da análise formal, já que os métodos nesta fase procedem por análise: visam ampliar o conhecimento sobre as formas simbólicas e, assim, desconstroem, dividem, quebram o cerco epistemológico, focando sua estrutura interna. Por sua vez, a interpretação/ reinterpretação procede por síntese, integra os elementos das formas simbólicas discutidos na análise formal à análise do contexto de sua produção. Assim, podemos dizer que essa é a fase de uma explicação interpretativa, fundamentada e plausivel. Thompson (2011) ainda lembra que um processo de reinterpretação é também um processo de interpretação me-

obra, seus elementos constitutivos e suas inter-relações; uma análise sintática buscaria perceber como a forma simbólica opera estruturalmente com a linguagem para dizer o que parece querer dizer; uma análise narrativa investiga como uma determinada história é contada, como uma trama se desenvolve; numa análise argumentativa verifica-se a harmonia da forma simbólica/obra. No caso de um livro, por exemplo, a sequência de assuntos, a estrutura de apresentação de cada assunto, sua coerência interna etc; por fim, uma análise da conversação estudaria as instâncias de interação linguística nas situações concretas em que elas ocorrem (p.126-127). 
diado pelos métodos sugeridos na HP, já que as formas simbólicas "são parte de um campo pré-interpretado, já são interpretadas pelos sujeitos que constituem o mundo sócio-histórico" (THOMPSON, 2011, p. 376). Podemos, então, dizer que o aspecto referencial das formas simbólicas fica mais evidente nessa fase, já que o intérprete busca entender o que elas representam, o que elas dizem do mundo social.

Assim, sustenta-se que as formas simbólicas devem ser compreendidas em relação aos contextos socio-históricos de sua produção, propagação e recepção, bem como no que se refere à sua estrutura interna. Thompson (2011), ao propor o referencial metodológico da HP, procurou mostrar como as diferentes análises podem ser integradas de maneira coerente, fornecendo um esquema intelectual que visa a apontar os aspectos múltiplos das formas simbólicas, buscando evitar as armadiIhas do internalismo - quando o texto se torna independente do contexto - e do reducionismo - quando o texto é construído específica e meramente em função do contexto.

\section{História Oral: breves considerações}

No campo da Educação Matemática, a História Oral começou a ser pensada no início dos anos 2000, e o interesse por essa abordagem de pesquisa tem sido cada vez maior. Os educadores matemáticos - particularmente os brasileiros, posto que foi no Brasil que esses estudos se iniciaram - têm, em diálogo com antropólogos, sociólogos, historiadores, psicólogos, artistas plásticos e filósofos, criado uma apropriação da História Oral desenvolvida nessas tantas áreas, para estudar aspectos relacionados ao ensino e à aprendizagem de Matemática.

A criação do Grupo de Pesquisa "História Oral e Educação Matemática" (GHOEM), no ano de 2002 , foi um elemento decisivo para o de- senvolvimento dessa perspectiva metodológica. Usando a História Oral, os pesquisadores desse Grupo têm desenvolvido pesquisas históricas - em História da Educação Matemática, mais particularmente - e pesquisas não-historiográficas, como aquelas que visam a estudar e implementar modelos alternativos para o ensino de Matemática na formação de professores de Matemática.

Ao trabalhar com a metodologia de História Oral, produzimos narrativas em momentos de entrevista. O narrado não é, e nem tem a pretensão de ser, o registro "real" do passado. Entendemos a elaboração de uma narrativa histórica como uma produção, e, como tal, ela tem um estatuto muito diferente da experiência vivida. Para Pinto (2015, p. 868), “o significado de expressões que nos remetem a um momento passado não é 'o momento passado em $\mathrm{si}^{\prime}$, mas o uso que se faz dessas mesmas expressões em um determinado jogo de linguagem". Desse modo, não há uma realidade para além do relato no qual nos apoiamos para nos aproximarmos do passado, para criar sentidos para um passado. As narrativas nos permitem problematizar e, ao fazerem isso, potencializam o que um sujeito, enraizado num tempo -espaço, fala sobre como percebe esse tempo e esse espaço a partir da memória que tem de outros espaços e tempos.

Ao entender a narrativa histórica como criação, as falácias, vícios, fantasias, incompletudes e lacunas que podem permear a oralidade só reforçam os aspectos subjetivos do narrado. A falibilidade do discurso humano, ao invés de resultar numa fraqueza, é uma força que possibilita a produção de múltiplas histórias, de variados sentidos. O trabalho com fontes orais assume e ressalta a multiplicidade dos pontos de vista, posto que não há "fato histórico" em si, mas somente o que dele pode ser (e é) dito. Gomes (2012, p. 128) afirma algo semelhante sobre as escritas de si: as "[...] dis- 
torções inconscientes ou falsificações deliberadas, em lugar de obstáculos, são indícios das realidades internas desses autores, e como tal, elementos a serem valorizados". Não sendo possivel o acesso ao acontecimento, o que existem, portanto, são elaborações realizadas a partir da memória do vivido. Nesse sentido, ao trabalhar com a oralidade, nos importam as interpretações que podemos produzir a partir do que o outro nos diz ter vivido, e não a mera checagem dos acontecimentos narrados, ainda que um cotejamento entre fontes de várias naturezas (orais, escritas, pictóricas, arquiteturais etc.) seja obrigatório no caso que pretendermos realizar, usando a História Oral, uma pesquisa historiográfica. $4 \mathrm{~A}$ verdade que defendemos é a da criação, e não aquela concebida como tesouro escondido que o pesquisador tem que revelar.

Essa ideia de uma pretensa verdade fica mais distante ainda das nossas propostas de ação em pesquisa, se entendermos que é sempre a partir do presente que falamos sobre o passado ou, ainda, que o passado é sempre criado no presente e, por isso, não há uma história pronta a se resgatar. Albuquerque Júnior (2007, p. 33) nos ajuda a entender essa construção ao dizer que "[...] é o presente que interroga o passado e o conecta com a nossa vida, com as suas problemáticas; o passado, como a História, é uma invenção do presente, embora ancorada nos signos deixados pelo passado". O que produzimos, portanto, são discursos. Elaborações que, uma vez manifestadas/criadas na/pela linguagem, ${ }^{5}$ são fi-

4 É importante ressaltar que a função da História Oral é criar narrativas a partir da oralidade. 0 uso dessas narrativas depende da intenção do pesquisador. Elas podem ser usadas como fermento para uma pesquisa historiográfica ou não. Assim, a presença do termo "História" na nomenclatura "História Oral" significa apenas que as narrativas geradas são fontes historiográficas, e não que essas fontes devam ser necessariamente usadas em uma pesquisa historiográfica.

5 Falar "História Oral" implica, mais usualmente, falar de oralidade; mas essa é uma disposição lacunar. Há estudos em curso que visam a praticar História Oral xadas pela escrita. Nenhum documento histórico é o reflexo inequívoco do acontecimento, do "real", mas elaborações intencionalmente produzidas por alguém em um determinado tempo e espaço. Os significados produzidos, seja em uma narrativa, seja a partir de vestígios físicos, são construções, fluxos inseridos em um movimento de transformação ao longo do tempo. Essa característica temporal é o que faz com que, no limite, não haja uma narrativa completa, acabada. o que fazemos ao narrar é registrar uma história.

Nos trabalhos que utilizam a História Oral seguem regulações e posturas metodológicas que têm sido vistas como estáveis. o modo como são produzidas análises a partir das narrativas elaboradas em momentos de entrevistas exige, aqui, algum refinamento. 0 primeiro ponto a ser ressaltado tem relação com as subjetividades presentes nas narrativas: como analisar vidas? Como encaixar em categoriais um discurso tão rizomático?

Tendo dados narrativos em mãos, Bolívar, Domingos e Fernández (2001) separam em dois polos distintos, mas não opostos, a análise desses dados: é possivel analisá-los paradigmaticamente ou narrativamente. Segundo os autores, há, portanto, uma análise paradigmática de dados narrativos e uma análise narrativa de dados narrativos. A análise paradigmática de dados narrativos consiste na elaboração de categorias, na maioria das vezes ilustradas por excertos, objetivando produzir algo próximo a uma generalização que, na maioria das vezes, tem a intenção de explicar o tema estudado. Na análise narrativa de dados narrativos, o resultado da análise é uma outra narrativa que busca elementos singulares que configuram uma história. Enquanto um modo busca o que há de comum,

tendo como depoentes sujeitos com deficiência de fala. Mesmo outras linguagens, como a pictórica, por exemplo, podem ser exploradas em pesquisas que mobilizam a História Oral. 
semelhante, entre as narrativas disponiveis, o outro busca a multiplicidade.

O trabalho do qual este artigo é um recorte tentou realizar uma análise narrativa de narrativas, operando, entretanto, de um modo singular, qual seja, mobilizando as diretrizes do referencial teórico-metodológico da Hermenêutica de Profundidade, tomando como forma simbólica as Licenciaturas Parceladas em Ciências - habilitação em Matemática, ocorrida nos anos de 1990 no Estado do Mato Grosso do Sul, e apoiando-se numa série de fontes documentais, com especial ênfase às fontes orais criadas segundo a metodologia da História Oral.

\section{Aproximação de perspectivas}

A discussão sobre a Hermenêutica de Profundidade como referencial teórico-metodológico para pesquisas no campo da Educação Matemática começou a tomar forma a partir dos anos 2000. Com o intuito de interpretar diferentes temas, a Hermenêutica de Profundidade foi utilizada acompanhada ou não de outras abordagens metodológicas. $^{6}$

Em 2006, ocorreu uma primeira tentativa de aproximar a Hermenêutica de Profundidade e a História Oral (HO), na tese de doutorado de Emerson Rolkouski (2006), que se propunha a trabalhar com metodologias cambiantes, posto que seu tema foi compreender os movimentos de formação e transformação (vivencial e profissional) do professor de Matemática. Nessa direção, o autor assinalou a exequibilidade de trabalhar com a HP na análise de

6 A ideia dos paratextos editoriais, proposta por Gerard Genette, mostrou-se potente aliada dos estudos em que a HP foi mobilizada para analisar uma forma simbólica específica, a saber, fontes escritas como livros de referência e manuais didáticos. Não tendo a intenção de abordar este tópico neste artigo, sugerimos ao leitor a consulta direta à obra de Genette (2009). entrevistas produzidas via HO. A ideia central foi fomentar reflexões teóricas e constituir alicerces para "leituras de vida", usando o referencial de John Thompson (2011), uma vez que o objetivo principal de sua pesquisa era o de compreender o que fazia com que o professor de Matemática se tornasse, ao longo de sua vida, o professor de Matemática que, naquele momento, era. Para isso, Rolkouski (2006) desenvolveu, a partir das narrativas criadas com seus entrevistados, uma abordagem baseada principalmente na análise socio-histórica das formas simbólicas, proposta por Thompson.

Oliveira (2008), Cardoso (2009) e Andrade (2012), que também mobilizaram a HP como referencial teórico-metodológico em suas pesquisas, discutem amplamente aspectos específicos do campo da Educação Matemática, ainda que não tenham usado, ao mesmo tempo, a perspectiva da História Oral. Essa série de trabalhos com a HP, entretanto, vai criando familiaridades com o referencial de modo que ele possa ser problematizado, mobilizado, ampliado e até mesmo subvertido com mais clareza e legitimidade. No ano de 2012, Garnica e Souza observam, a partir dos estudos de Oliveira (2008), que apesar deste autor conceber os livros didáticos como forma simbólica, uma das suas principais intenções é que outros pesquisadores possam "ter indicativos de como analisar as formas simbólicas - quaisquer que sejam elas - que deseje tomar como objeto de estudo" (GARNICA; SOUZA; 2012, p. 90, grifo nosso).

Por essa vertente, o artigo de Andrade e Oliveira (2014) explicita a possibilidade de vincular HP e HO, ressaltando dentre as várias afinidades apresentadas entre os referenciais, que a HP pode ser mobilizada na análise de narrativas, uma vez que ambas privilegiam a multiplicidade de interpretações como forma de compreensão. Além disso, os autores discutem que as pesquisas em HO podem colaborar 
de modo muito significativo para a análise socio-histórica, uma das fases da HP. Consideramos, ainda, que as narrativas em História Oral, criadas a partir da oralidade em momentos de entrevista, tornam-se textos escritos nos movimentos de transcrição e textualização, sendo, portanto, formas simbólicas como as tratadas por uma série de pesquisadores, alguns dos quais já citados aqui.

Em 2014, um exercício mais efetivo quanto à tentativa de vincular $\mathrm{HO}$ e HP foi desenvolvido por Viviane Aparecida Bagio (BAGIO, 2014), na dissertação de mestrado em que a autora analisa, sob a ótica da HP, as diversas versões das Diretrizes Curriculares da Educação Básica do Estado do Paraná (DCE), as propostas de implementação publicadas oficialmente e as narrativas de colaboradores que tinham afinidade com esse tema de estudo. Assim, ela toma como forma simbólica as entrevistas e considera como elementos para a análise socio-histórica os Parâmetros Curriculares $\mathrm{Na}$ cionais, o Currículo Básico para Escola Pública do Estado do Paraná e as Diretrizes Curriculares da Educação Básica do Estado do Paraná. Além disso, considera as ações da Secretaria Estadual de Educação para a implementação das DCE para constituir a análise formal-discursiva, ao mesmo tempo em que se vale de narrativas, produzidas segundo as diretrizes da HO, para auxiliar no movimento da reinterpretação.

A partir desses exercícios, sobre os quais Garnica (2015, p. 47) conclui que "é possivel empregar a história oral no interior de uma hermenêutica de profundidade, do mesmo modo como é possivel usar a hermenêutica de profundidade para analisar narrativas produzidas a partir da história oral", buscamos vincular a HP e a HO para compreender os movimentos de implantação e desenvolvimento das Licenciaturas Parceladas no Estado de Mato Grosso do Sul.

\section{Por que a ênfase no conceito de ideologia?}

Inspirados, então, na Hermenêutica de Profundidade, nosso relatório de pesquisa foi constituído, ao todo, por cinco tópicos, dois deles voltados ao que Thompson (2011) chama de análise socio-histórica, outros dois em que se intenciona desenvolver uma análise formal ou discursiva e, por fim, um tópico que sintetiza o percurso de compreensões que nos foi possivel percorrer (e que se aproxima da fase de interpretação/re-interpretação que, de todo modo, já vinha sendo feita nos tópicos anteriores, dada a indissociabilidade desses movimentos de análise na HP). Apesar dessa apresentação ordenada e feita por partes, é importante reiterar que os movimentos de análise, na realidade, ocorrem em sincronia. A elaboração escrita, entretanto, exige uma apresentação mais linearizada, como alerta Andrade (2012): "se a elaboração é, digamos, mais caótica, plena de idas e vindas, o registro dessa elaboração, sua forma textual 'final' é calma, e pacificamente se rende à linearização" (ANDRADE, 2012, p. 266).

Foi em meio a esse movimento analítico que percebemos várias relações estruturadas socialmente que evidenciavam, no caso das Licenciaturas Parceladas, o estabelecimento e a sustentação de redes de dominação. Isto nos levou, nesse momento, a um conceito central nas elaborações de Thompson (2011), o de ideologia. Esse autor repensa esse termo à luz do desenvolvimento dos meios de comunicação de massa, tema central de suas investigações sociológicas. Em nosso trabalho, o conceito de ideologia nos leva a problematizar como, em determinados contextos, com determinadas relações de dominação e de luta pelo poder, foram constituídas e desenvolvidas as propostas das Licenciaturas Parceladas, que habilitaram professores para ensinar Matemática num 
campo geográfico e num tempo específicos. É importante lembrar que apreender a ideologia das formas simbólicas, criando sentidos para os modos como ocorre a distribuição assimétrica de poderes na sociedade, é o objetivo da HP, daí a importância desse conceito para nossos estudos.

\section{O conceito de ideologia}

Como sugere Thompson (2011), buscamos iluminar as condições sociais e as características estruturais das Licenciaturas Parceladas que habilitavam professores de Matemática no Estado do Mato Grosso do Sul, nossa forma simbólica, visando a interpretar esse modo de formação e explicitar, tanto quanto possivel, “a conexão entre o sentido mobilizado pelas formas simbólicas e as relações de dominação que esse sentido mantém" (THOMPSON, 2011, p. 35). Antes, porém, apresentaremos em linhas gerais o modo como concebemos a noção de ideologia.

Para tratar o conceito e desenhar uma teoria da ideologia, Thompson (2011) retoma alguns contornos e desacertos ocasionais que, ao longo dos últimos dois séculos, ocorrem quando o termo ideologia é mobilizado. Ele formula, assim, uma concepção ideológica a partir de um breve histórico, buscando detectar algumas particularidades que, no tempo, são conservadas, e, ao mesmo tempo, tenta se afastar de conjecturas que a ele parecem insustentáveis.

Thompson ressalta em suas observações que o conceito de ideologia, devido à longa trajetória percorrida em um caminho sinuoso, carrega uma gama de significados. Por isso, observa que, hoje em dia, tratar de ideologia, muitas vezes, significa enfocar o pensamento do outro que pensa diferente de nós. Nessa perspectiva, caracterizar "um ponto de vista ideológico é, tem-se a impressão, já criticá-lo implicitamente, pois o conceito de ideologia parece transmitir um sentido negativo, crítico" (THOMPSON, 2011, p. 14).

Considerando a multiplicidade de significados vinculados ao conceito, Thompson sugere haver uma ramificação entre elas, abrindo dois caminhos: num deles, estão as concepções que Thompson (2011) chama de neutras, no outro, as concepções críticas, ambas ocorrendo, na história, de modo muito intenso. As concepções neutras podem ser observadas, segundo Thompson (2011) nas obras de autores como Destutt de Tracy, Lenin e Lukács, e visam a compreender a ideologia como um aspecto da vida social ou forma de investigação social como outra qualquer, não menos nem mais interessante ou questionável. Desse modo, nessa forma de apreender o conceito, um fenômeno entendido como ideológico não precisa estar ligado aos interesses de um grupo específico. As concepções críticas de ideologia, segundo Thompson, podem ser detectadas em Napoleão e Marx, por exemplo. Trata-se de uma concepção restrita de ideologia, segundo a qual fenômenos caracterizados como ideológicos carregam implicitamente um criticismo e, dessa forma, estão carregadas com um sentido pejorativo, crítico ou negativo, tendo sempre a ideia de ilusório e enganador.

Segundo Thompson (2011), atualmente, na literatura social e política, há duas respostas que se destacam na herança ambígua do conceito de ideologia: a tentativa de domar o termo e a de abandoná-lo. Na busca por domar o conceito, tenta-se, explícita ou implicitamente, retirar dele um sentido negativo e integrá -lo a um conjunto de conceitos utilizados pelas ciências sociais. Essa investida criou o que se denomina, na atualidade, de concepção neutra da ideologia. Nesse viés, as ideologias podem ser vistas como sistemas simbólicos de pensamento ou de crenças, sendo função do analista identificar e descrever, a partir desses 
sistemas, a dinâmica da ação social e política. Há, nesse viés, a propensão de pensar as ideologias em termos de ismos - marxismo, comunismo, conservadorismo etc. Quanto à opção pelo abandono do termo, esta deve-se à ideia de que o conceito de ideologia é muito ambíguo, contestado e elástico ao ponto de ter sido utilizado e marcado historicamente de diversos modos, acreditando-se, assim, hoje em dia, que ele não favorece uma análise social e política. Tal resposta é apontada por Thompson (2011) como superficial, pois esse viés prefere abandonar a busca por detectar algum resíduo digno de ser conservado. Para o sociólogo - que apresenta outra noção de ideologia que difere dessas duas -, o conceito continua adequado e significativo no vocabulário intelectual da análise política e social. Assim, Thompson (2011) não tenta eliminar seu sentido negativo, mas mantê-lo e desenvolvê -lo criativamente.

Contudo, Thompson não defende especificamente uma ou outra teoria particular dentre as apresentadas anteriormente. 0 que ele faz é tentar conservar algumas conjecturas ao mesmo tempo em que abandona alguns temas implícitos nas teorias. Neste sentido, a reformulação apresentada por Thompson (2011) mostra-se como construtiva, posto que tenta elaborar um conceito de ideologia ao invés de retomar algum dos já cristalizados. Essa é, como ele próprio adianta, uma elaboração modesta, já que não busca realizar uma síntese das mais variadas concepções, destacandose aquelas que, segundo seu ponto de vista, são mais significativas.

Para formular sua concepção de ideologia, Thompson (2011) apoia-se no que ele denomina "a concepção latente" de Marx. Ele mantém, mas de uma forma modificada, somente um critério de negatividade que, para ele, é uma característica definidora de ideologia: uma ideologia sustenta relações de dominação.
Não é necessário que as formas simbólicas sejam ilusórias, incorretas ou equivocadas para serem ideológicas, mas em alguns casos, elas podem operar por meio do ocultamento e do mascaramento das relações sociais, por meio da falsa interpretação de situações ou até mesmo do obscurecimento, que, porém, para ele, não são características fundamentais da ideologia, são apenas possibilidades circunstanciais. Observa, ainda, que há mais dois aspectos em que a sua reformulação difere, de modo expressivo, da concepção de Marx. O primeiro desses aspectos está no próprio critério de sustentação de relações de dominação que, na obra de Marx, é entendido em termos de relações de classe. Assim sendo, tem-se, para Marx, como eixos principais da exploração e da desigualdade nas sociedades humanas, em particular nas sociedades capitalistas, as relações de dominação e subordinação de classe. Para Thompson (2011), porém, as relações de classe não são o único meio pelo qual operam a dominação e a subordinação, ainda que sejam um eixo para compreendê-las. Para ele, estudar a ideologia implica atentar para os modos como o sentido mantém relações de dominação de classe, mas também precisamos investigar outros tipos de dominação que existem nas relações sociais estruturadas. Nossas interpretações/reinterpretações devem ser vistas para além do fato de classes dominantes lutarem e unirem-se sempre visando perpetuar seus interesses, ambições e decisões, empenhando-se para assegurar e conservar a posição de dominação. Para Thompson (2011), a ideologia não depende necessariamente das relações de dominação de classe: o autor abre a análise da força simbólica a outros modos de dominação, não reduzindo as ideologias nas sociedades modernas a simples reflexos das estruturas econômicas e sociais.

O segundo aspecto que explicita uma divergência entre Thompson (2011) e Marx é que, 
na teoria de Marx, as "classes existem 'em si mesmas', determinadas por relações objetivas de produção e por circunstâncias que são, primeiramente, de caráter econômico" (THOMPSON, 2011, p. 78). Esse sentido, atribuído por Marx às classes sociais, provoca Thompson (2011) que, por sua vez, argumenta que a "dificuldade com essa teoria é que ela tende a menosprezar o quanto as formas simbólicas e o sentido mobilizado são constitutivos da realidade social e estão ativamente envolvidos tanto em criar como em manter relações entre pessoas e grupos" (THOMPSON, 2011, p. 78). Thompson (2011) propõe, assim, na sua reformulação, conceituar a ideologia em termos dos modos como o sentido é mobilizado pelas e a partir das formas simbólicas, podendo servir para manter e reproduzir relações de dominação. Busca-se, dessa forma, evitar que a ideologia seja vista como o "cimento social" que consolida as sociedades, unificando os seus integrantes, em termos de normas e valores coletivamente compartilhados. Ademais, essa reformulação proposta impede pensarmos que as formas simbólicas são ideológicas em si mesmas. Para Thompson (2011), o quanto elas são ideológicas e se são ideológicas resulta dos modos como elas são empregadas e entendidas em contextos sociais específicos.

$\mathrm{Na}$ busca, então, por criar um guia para a análise das formas simbólicas, Thompson (2011) reformula e apresenta a sua compreensão de ideologia:

Na reformulação do conceito de ideologia procuro reenfocar esse conceito numa série de problemas que se referem às inter-relações entre sentido (significado) e poder. Argumentarei que o conceito de ideologia pode ser usado para se referir às maneiras como o sentido (significado) serve, em circunstâncias particulares, para estabelecer e sustentar relações de poder que são sistematicamente assimétricas - que eu chamarei de 'relações de dominação'. Ideologia, falando de uma maneira mais ampla, é sentido a serviço do poder (THOMPSON, 2011, p. 16 , grifo do autor).

Cabe-nos, desse modo, se desejamos seguir a perspectiva proposta por Thompson (2011), buscar modos de como o sentido é constituído e empregado pelas e a partir das formas simbólicas e se serve ou não (e como) para sustentar e estabelecer relações de poder.

Sob essa óptica, o sociólogo nos desafia a estudar as formas simbólicas à luz das relações sociais estruturadas. Estudar a ideologia, neste sentido, não envolve analisar um sistema de pensamento ou crença ou tentar analisar uma forma simbólica "em si mesma": trata-se de entender os usos sociais das formas simbólicas. Procura-se, ainda, investigar as relações de poder e dominação para além das relações de poder institucionalizadas. Assim, o olhar analítico deve se voltar também para as relações que ocorrem nos contextos sociais que atingem diretamente a maioria das pessoas em suas vidas cotidianas, como, por exemplo, no local de trabalho, nas vizinhanças da (e na) própria casa. Assim, estamos interessados tanto no contexto específico das instituições formais quanto no contexto da vida cotidiana.

Com base nessas ideias, explicitamos que o conceito de ideologia aqui utilizado:

[...] chama a atenção para as maneiras como o sentido é mobilizado a serviço de indivíduos e grupos dominantes, isto é, às maneiras como o sentido é construído e transmitido pelas formas simbólicas e serve, em circunstâncias particulares, para estabelecer e sustentar relações sociais estruturadas das quais alguns indivíduos e grupos se beneficiam mais que outros, e que alguns, indivíduos ou grupos, têm um interesse em preservar, enquanto outros procuram contestar. (THOMPSON, 2011, p. 96)

Por isso, na tentativa de compreender todas as mudanças socio-históricas que permitiram a produção do nosso objeto de estudo, bem como sua propagação e apropriação, lan- 
çamos mão do conceito de ideologia como reformulado por Thompson (2011). Tal conceito desempenha papel fundamental "nas batalhas políticas da vida cotidiana" (THOMPSON, 2011, p. 43), afinal, há várias situações de dominação que entendemos ser relações de poder sistematicamente assimétricas. Para Thompson, essas situações ocorrem "quando grupos particulares de agentes possuem poder de uma maneira permanente, e em grau significativo, permanecendo inacessivel a outros agentes, ou a grupos de agentes, independentemente da base sobre a qual tal exclusão é levada a efeito" (THOMPSON, 2011, p. 80). Assim, uma forma simbólica será ideológica quando estabelecer e sustentar relações de dominação em um contexto socio-histórico determinado, e será crítica quando auxiliar a minar e subverter essas relações. Nesse viés, sabendo que nenhuma forma simbólica é ideológica ou contestatória em si mesma, podemos entendê-la como ideológica em um determinado contexto e subversiva em outro, como ideológica em alguns aspectos e contestatória em outros.

De um modo mais pragmático, Thompson (2011) indica ser necessário analisar as pessoas envolvidas na produção, transmissão e recepção das formas simbólicas como sujeitos ativos, que, apesar de poderem ser, de certa forma, influenciados por essa produção, também são capazes de ter um pensamento crítico e independente na busca de reinterpretar e compreender as mensagens que recebem, um exercício que, muitas vezes implicitamente, permite aos sujeitos compreenderem a si próprios. Nisso parece residir um ponto central em nossa perspectiva que se apoia na vinculação entre HP e HO: se mobilizamos a HP para compreender as Licenciaturas Parceladas (nossa forma simbólica), a HO, por meio da produção de narrativas específicas, nos permite ouvir e registrar os modos subjetivos como as pessoas envolvidas com essas Licenciaturas atribuem significado a esse modo emergencial de formação docente.

A ideologia opera de diferentes modos, por estratégias pautadas na legitimação, por dissimulação, por unificação, por fragmentação e/ ou por reificação. Uma síntese desses modos pelos quais a ideologia opera pode nos ajudar a compreender a sequência deste nosso texto, organizado, como se apresenta nos próximos parágrafos.

As operações de legitimação impõem-se quando as relações de poder - ou a necessidade de dominação - são apresentadas como justas e dignas de apoio, legítimas. As estratégias para a legitimação podem implicar (a) racionalização (o produtor da forma simbólica constitui uma cadeia de raciocínio para justificar ou defender as relações), (b) universalização (implica apresentar o interesse de alguns como sendo o interesse de todos), (c) narrativização (cria-se uma narrativa visando a impor um passado que faz do presente algo natural, eterno e aceitável); já segundo a dissimulação, as relações de poder são estabelecidas e sustentadas por serem negadas, obscurecidas, dissimuladas, lançando mão de estratégias como as de: (a) deslocamento (que ocorre quando conotações positivas ou negativas de um termo habitualmente utilizado para referir-se a determinadas pessoas ou objetos são transferidas para um novo referente), de (b) eufemização (que se dá quando descrições de instituições, ações ou relações sociais são mobilizadas para acrescentar uma valoração positiva ao que se deseja impor), de (c) tropo (trata-se do uso de figuras de linguagem no discurso que visa a defender/impor/perpetuar as relações de dominação. As formas mais frequentes de tropo que podem ser utilizadas para dissimular relações de dominação são a metáfora, a metonímia e a sinédoque ${ }^{7}$ ).

7 Metáfora, Metonímia e Sinédoque são figuras de linguagem. Na metáfora, usa-se palavra ou expressão em um sentido não muito comum, visando a uma in- 
Para manter relações assimétricas de poder, pode-se agir pautado na ideia de unificação, o que ocorre quando se busca vincular indivíduos numa identidade coletiva - independente de divisões e diferenças - por meio de uma construção simbólica de unidade. São estratégias para esse fim: (a) a padronização (a adequação de formas simbólicas a um referencial padrão) e (b) a simbolização (que se dá quando uma identidade "comum" passa a ser representada por símbolos que criam uma unidade e uma identificação coletiva). Podese, também, visar à fragmentação, buscando excluir pessoas e segmentar grupos que ameaçam uma determinada relação de dominação. Para fragmentar, são válidas as estratégias de: (a) diferenciação (enfatizar as distinções entre pessoas pode implicar o enfraquecimento, a desunião e o decorrente desmantelamento de grupos) e (b) de expurgo do outro (alguns agentes são demonizados, visando à criação de inimigos). Por fim, a reificação, um dos modos pelos quais a ideologia opera, mantendo as relações de dominação, é a tentativa de eliminar o caráter socio-histórico tentando fazer crer que uma situação transitória, histórica, é permanente, natural, atemporal. Para reificar, pode-se apostar nas estratégias de: (a) naturalização (tratar como natural um estado de coisas e fazer acreditar ser social e histórico um acontecimento que na verdade é episódico), de (b) eternização (trata-se de apresentar os fenômenos socio-históricos como se fossem permanentes e imutáveis, o que implica a necessidade de esvaziá-los de seu caráter histórico), de (c) nominalização/passivização (isto é, descrevendo ações específicas e no-

terpretação por semelhança (como em “Meu coração é um balde despejado" - Fernando Pessoa). A metonimia centra-se na similaridade entre dois termos ou expressão (como em "Completou dez primaveras" para significar "Completou dez anos). A sinédoque é um tipo de metonímia em que se usa a parte para significar o todo (como em "Onde falta pão, todos falam e ninguém tem razão"). meando os que participam dessas ações de modo a culpabilizar, objetiva e especificamente, alguém ou algo. A passivização acontece, por exemplo, quando na narrativa os verbos são colocados na voz passiva, ${ }^{8}$ apagando os sujeitos como se os acontecimentos ocorressem "por si próprios").

Explicitadas essas considerações relativas à HP e à noção de ideologia, passamos a apresentar, segundo nossa compreensão, alguns dos sentidos atribuídos às Licenciaturas de Ciências - Habilitação em Matemática, ocorridas em regime parcelado, no Mato Grosso do Sul.

\section{Uma compreensão sobre as Licenciaturas de Ciências - Habilitação em Matemática em regime parcelado}

\section{As Parceladas da década de 1990}

Em um novo Estado que conseguiu sua autonomia sob a e devido à ditadura militar, os veIhos hábitos foram mantidos e permaneciam de modo enérgico, principalmente no que diz respeito à luta pelo poder. Apesar de pertencerem à mesma classe social, os políticos não formavam um grupo homogêneo nem dentro dos próprios partidos ${ }^{9}$ e, assim, cada segmento lutava por cargos públicos, principalmente pelo de governador, o cargo mais visado. Para nós, esse é um dos exemplos mais explícitos, em nosso trabalho, de como as relações de poder, da forma entendida por Thompson (2011),

8 As vozes ativa e passiva são formas assumidas pelos verbos para indicar quem é agente ou paciente da ação ("Ele fez o trabalho" - voz ativa; "O trabalho foi feito por ele" - voz passiva). Na voz passiva, portanto, o sujeito da frase recebe a ação expressa pelo verbo.

9 Como ocorreu quando da divisão dos partidários do sul e do norte, no Mato Grosso Uno, no Partido Social Democrático (PSD) e na União Democrática Nacional (UDN), depois da divisão do Estado houve uma nova ruptura: a Aliança Renovadora Nacional (ARENA) estadual fica dividida em dois grupos, os independentes - liderados por Pedro Pedrossian - e os ortodoxos liderados por José Fragelli. 
podem ocorrer numa mesma classe. Nesse viés, nossa atenção volta-se para outro tipo de dominação, que nesse caso são as relações sociais estruturadas na política.

Podemos afirmar, após nossos estudos, que os conflitos pelo poder já eram intensos entre os sulistas antes mesmo da divisão, e o discurso predominante dos sulistas pautava-se, em uníssono, na contrariedade quanto à dominação pelo norte. Nesse viés, como dominados, os políticos do sul mostravam-se, segundo Silva $(2015$, p.76) "abertos a todas as iniciativas e desinteressados de cargos públicos". Contudo, a constatação de Silva (2015), em seus estudos, é de que desde 1945 os dois partidos existentes no país e, consequentemente, no Estado em foco - o Partido Social Democrático, PSD, e a União Democrática Nacional, UDN -, revezavam-se no governo do Mato Grosso Uno. 0 Mato Grosso Uno, porém, se diferenciava de outros estados em um ponto: internamente ao partido já havia uma severa e conhecida divisão: havia o PSD/sul e o PSD/norte, a UDN/sul e a UDN/norte. No entanto, o revezamento entre os partidos não acontecia do mesmo modo entre os partidários: Silva (2015) observa que o governo do Estado de Mato Grosso Uno esteve por mais vezes nas mãos dos políticos do sul. Nesse sentido, reforça-se a ideia da luta pelo poder ser, desde a época do Mato Grosso Uno, uma característica evidenciada dos políticos do sul.

Todavia, o Estado que sempre teve na criação de gado seu carro-chefe, com suas grandes propriedades rurais, preservava também a hegemonia de dirigentes no cenário político. Por muito tempo após a divisão permanecia a alternância entre governadores de partidos distintos, Pedro Pedrossian (PTB) e Wilson Barbosa Martins (PMDB), gerando diversos entraves e um grande problema financeiro ao novo Estado. A esse respeito podemos citar o primeiro governo de Wilson Barbosa Martins, iniciado em 1982, e que, especificamente para a Educação, apoiou a democratização, com investimentos para a melhoria dos salários docentes e também na infraestrutura. No entanto, os governos que o sucederam, tanto o de Marcelo Miranda Soares, do mesmo partido, como o de Pedro Pedrossian, são marcados pelo arrocho salarial e pela grande desvalorização da Educação. As administrações de Marcelo Miranda Soares e de Wilson Barbosa, em decisões contraditórias, permitem perceber a fragmentação que marca este cenário, tanto que Wilson Barbosa Martins, que havia apoiado a candidatura de Marcelo Miranda Soares na tentativa de evitar transferir a conotação negativa do governo deste último peemedebista a todo o partido, deixa o PMDB para ingressar no PSDB.

Durante a década de 1990, esse desconcerto político continuou e acabou se refletindo em todas as esferas econômicas do Estado. 0 Estado que se mostrava promissor aos olhos dos migrantes e imigrantes que apostavam na oportunidade de ocupar terras, devido ainda aos reflexos dos diversos projetos de desenvolvimento do Centro-Oeste implantados após a divisão do Mato Grosso Uno, agora sofria com a crise agrária e com o alto percentual de crescimento urbano. Dessa forma, houve uma expansão desenfreada do Estado, necessitando de mais professores, mais escolas, mais salas de aula, o que ia na contramão das políticas educacionais implementadas nos governos de Marcelo Miranda e Pedro Pedrossian. A falta de incentivo à área da Educação nesses dois governos implicou um grande desinteresse pela profissão. Além disso, havia carência de cursos específicos de formação de professores no Estado, como observado nas narrativas de nossos colaboradores. Restava, desse modo, para atender a ampla demanda, principalmente do interior do Estado, valer-se da atuação de professores sem formação específica. Conforme nos explica o professor Antônio Carlos do Nas- 
cimento Osório, colaborador dessa pesquisa, foi nesse cenário que um estudo, financiado pelo Instituto Nacional de Estudos e Pesquisas Educacionais Anísio Teixeira - INEP, confirmou o que historicamente já se podia notar: uma quantidade elevadíssima de professores leigos atuando na rede estadual de ensino, principalmente no interior do Estado, que, devido à grande extensão territorial, aumentava dia a dia de maneira caótica e desenfreada. Nossos colaboradores na pesquisa que deu origem a este texto, salientam, em suas narrativas, que a falta de professores formados tanto nas Universidades Públicas quando nas Faculdades Privadas implicou a necessidade de contratar professores leigos.

Para responder à necessidade social da escassez de professores habilitados no Estado, segundo o professor Antônio Carlos do Nascimento Osório, foi elaborado e proposto em 1990 o projeto chamado Interiorização do Ensino de Graduação. O foco era atender o público do interior que já atuava na rede estadual de ensino, sem prejudicar (ainda mais) o sistema educacional público. Dessa forma, os cursos seriam ofertados e realizados em regime parcelado e planejados para ocorrer no período de férias escolares. Mas por que, podemos perguntar, não oferecer (ou também oferecer) mais vagas nos cursos regulares da UFMS, ao invés de (só) oferecer cursos emergenciais?

Dois principais motivos podem ser destacados. O primeiro é que apenas quatro polos da UFMS - Campo Grande, Três Lagoas, Dourados e Corumbá - mantinham cursos de Licenciatura em Matemática no início da década de 1990 (apenas em 1997 foi criado o curso de Licenciatura em Matemática em Aquidauana). Somente esses polos não conseguiam atender o interior do Estado, já que havia o problema de deslocamento, apontado por nossos colaboradores. As estradas precárias eram um limitante significativo - levava-se horas para chegar a cidades vizinhas. Por isso os professores do interior que lecionavam em cidades vizinhas a esses polos não conseguiriam lecionar em uma cidade e estudar em outra. Um segundo ponto registrado praticamente em todas as narrativas dos nossos colaboradores é o fato de que a formação de professores, principalmente na área de exatas, inclusive nas Universidades Públicas, não era, à época, propriamente voltada a atender a rede pública de ensino básico,10 principalmente para os interiores. A esse respeito, nos diz o professor Celso Correia de Souza:

Sei que tem ano aqui na Federal que o curso de Física não forma ninguém. Então, é uma característica desses cursos. Primeiro, exige do aluno o tempo todo, né? É um curso integral e é puxado, e muito puxado mesmo. Eu não vou afirmar categoricamente que seria isso mas, parece que a preocupação está em formar os alunos para darem prosseguimento aos estudos, para fazer mestrado, doutorado, e não para ensinar no ensino fundamental e médio. 0 nosso ensino é muito precário, né? Então, talvez, seja um luxo um aluno formado na Federal lecionar no ensino fundamental, em uma periferia, numa cidade muito pequena. Um aluno muito bem formado está mais pensando em progredir. Isso era o que acontecia na época, não tinha professor, e esse aluno que era formado na Federal prosseguia o estudo, já saía com bolsa para mestrado, para doutorado, era esse o problema. (Entrevista do professor Celso Correia de Souza)

A parte pedagógica - que auxiliaria os alunos a entender a relação estudante-professor e compreender o processo de ensino na escola, bem como a incorporar metodologias com as quais deveria/poderia trabalhar - eram denominadas, pelos próprios professores, "perfumaria". A esse respeito, nos diz o professor Luiz Carlos Pais que o que se pensava era que “o professor de Matemática tinha que saber

10 Corroboram essa afirmação outros depoimentos, como aqueles coletados e disponibilizados por Carla Regina Mariano da Silva, em sua pesquisa de 2015. 
só conteúdo e a formação deveria ser voltada para a Matemática Pura, sendo desprezados os conteúdos voltados para o ensino". Tão desprezados que os alunos identificados com o magistério, segundo a narrativa deste nosso colaborador, "eram desestimulados e até mesmo perseguidos".

Essa crítica, voltada aos professores da Universidade, mostra um curso muitas vezes segmentado - como explica o professor Sidnei Azevedo de Souza -, dividido entre os professores que lecionam disciplinas pedagógicas e aqueles que lecionam "Matemática mesmo". Essa situação explicita claramente a fragmentação que ocorre não somente em escolas públicas, e nem somente nos tempos de então.

Considerando todo esse discurso que circulava no curso de Matemática da UFMS no período estudado, o curso de licenciatura era tratado como um bacharelado, o que, na visão do professor Sidnei Azevedo de Souza, acabava "prejudicando o curso de licenciatura em Matemática". Sob essa afirmação, esse colaborador nos explica que se:

[...] o conteúdo em si é bem trabalhado, mas se também não trabalhar a parte pedagógica os alunos vão para sala de aula e não ficam, levam um choque. Isso porque muitas vezes o acadêmico não sabe trabalhar aquele conteúdo que foi trabalhado com ele na Universidade e fazer a transposição para a sala de aula da escola. Penso assim, que muitas coisas precisam ser pensadas quando se trata de licenciatura. (Entrevista do professor Sidnei Azevedo de Souza)

Vale notar que essa marca de desprestígio de formação pedagógica se torna um problema para as licenciaturas em regime parcelado, pois para que elas acontecessem era necessário não somente seguir a mesma estrutura do curso regular, mas também cativar e contar com o apoio e a disposição dos professores que atuavam nos cursos regulares da UFMS. Esse é um dos pontos focais da nossa análise, pois vários professores, segundo o professor Antônio Lino Rodrigues de Sá, não aceitavam o convite para atuar nas licenciaturas em regime parcelado, mesmo recebendo pró-labore pelas aulas ministradas. Além disso, muitos dos que iam, como aponta o professor Edmir Ribeiro Terra, trabalhavam da mesma forma que nos cursos regulares da universidade, o que, na visão desse colaborador, foi um dos maiores entraves enfrentados nos cursos, resultando na reprovação e/ou na desistência de muitos alunos do curso de Ciências - habilitação em Matemática. Segundo nosso ponto de vista, a tentativa de padronização, naturaliza$\mathrm{da}$, como se fosse assim por ter que ser assim, sem adaptação alguma aos cursos emergenciais e seus professores-alunos, era justificada pelo discurso de que as licenciaturas em regime parcelado deveriam ajustar-se a um referencial que, à época, era o padrão e, portanto, legítimo. Desprezando as diferenças de oportunidade e defendendo a necessidade de igualdade de condições - já que ambos os cursos, regular ou parcelado, formariam um mesmo profissional - o discurso da unificação e da igualdade serve para desunir e acentuar as desigualdades. Os idealizadores das Licenciaturas Parceladas da década de 1990, em momento algum, como observa o professor José Luiz Magalhães de Freitas, tentam diferenciar a formação regular das parceladas. Ao contrário, tentaram oferecer o mesmo tipo de formação, o que, se pode ser visto como uma forma de não desprestigiar uns em detrimento de outros, pode ser expressão que confere o mesmo peso a medidas bastante distintas.

O maior problema da reprovação e da desistência, na visão do professor Antônio Lino Rodrigues de Sá, era que os alunos "que iam sendo reprovados voltavam para sala de aula e continuavam sendo professores de Matemática", perpetuando a condição de leigos. Esse fato chama muito a atenção deste nosso de- 
poente, à época coordenador, que tenta solucionar o problema escolhendo professores da Universidade para fazer a eles convites específicos, específicos para atuarem no curso, além de acompanhar o trabalho desses convidados. Assim, tenta-se, nas palavras do professor Antônio Lino, "manter o nível e a seriedade" de um curso de licenciatura, buscando, sobretudo, adaptar a proposta à realidade dos alunos.

Desse conjunto de mudanças e estratégias para proporcionar aos professores leigos uma formação, decorre a ruptura de um paradigma que, na visão do professor Luiz Carlos Pais, é aquele que visa uma "formação exclusiva para a pós-graduação em Matemática".

É nesse contexto que essas licenciaturas são ofertadas e desenvolvidas, apesar das dificuldades, o que, paradoxalmente, leva a uma avaliação positiva desse modelo de formação por parte dos nossos colaboradores. Isso porque, como nos explica o professor Antônio Carlos do Nascimento Osório, não era "a meIhor formação, não era do tipo ideal, mas era o espaço que se tinha. Era como se podia trabaIhar naquela época":

[...] se eu for comparar a qualidade da formação dos professores, eu vou ser bem franco para você, não tem como eu te mostrar isso, mas eu posso te dizer que para os professores que participaram foi uma coisa que, vamos dizer, caiu do céu. Não tinha outra opção, né? Quer dizer, para a maioria deles, eles jamais cursariam um curso superior. Então, eles tiveram uma outra relação com o projeto que não era simplesmente a formação. Eles se situavam na valorização, no respeito, na oportunidade, em um monte de coisas aí. Assim, eu tenho certeza absoluta que, para a maioria, se não fosse o projeto, eles não teriam feito um curso superior. (Entrevista do professor Antônio Carlos do Nascimento Osório)

É perfeitamente aceitável, neste viés, para nossos colaboradores, que esses cursos "eram o que podia ser feito", afinal, como observa o professor Antônio Lino Rodrigues de Sá, com ou sem formação específica em Matemática e/ ou em Ciências, eles continuariam lecionando. Por isso, é recorrente nas falas dos coordenadores e professores a ideia de que melhor pouco do que nada. Na visão do professor Edmir Ribeiro Terra, esse pouco não prejudicava a atuação deles enquanto professores, pois "você precisa saber um pouco mais do que você vai ensinar e eles estavam aprendendo um pouco mais do que eles iriam ensinar". Ofereceram, assim, um curso que, nas palavras do próprio idealizador do projeto, foi uma formação ao menos parcial.

Segundo as avaliações desses mesmos depoentes, o curso foi benéfico e proveitoso, até mesmo porque, na visão deles, era uma oportunidade única para aqueles professores leigos do interior terem algum tipo de formação, e isso fazia com que, por exemplo, os professores que atuavam nessas Licenciaturas tivessem afeição pelos alunos, como registrado pelo professor Antônio Lino Rodrigues de Sá: “A gente sentia prazer, porque se a gente não desse a formação para eles, lá, eles iam continuar sendo professores de Matemática de qualquer forma", e também na narrativa do ex-aluno da Licenciatura em regime parcelado, Antônio Enes Nonato: “Se nós não tivéssemos feito as Parceladas, na época, nós não teríamos feito um curso superior, porque tínhamos que continuar trabalhando". Antônio continua:

Essa Licenciatura Parcelada de Matemática contribuiu muito para a parte didática, com o modo como eu trabalhava em sala de aula. Melhorou muito meu trabalho com os alunos, porque, no início, eu passava informação né? Eu acho que eu era um passador de informação. Você entende? Depois, eu já fazia as coisas com segurança, com decisão. Eu sabia o que estava falando e se estava falando A e T, é porque eu queria A e T. Anteriormente, eu passava esse aqui foi o autor fulano de tal, fulano que disse, mas, depois, eu assumi aquilo para mim como se fosse meu. Por 
isso eu acho que contribuiu muito, né? (Entrevista do aluno Antônio Enes Nonato)

As Licenciaturas de Ciências - Habilitação em Matemática em regime parcelado, em nosso trabalho, são apresentadas como dignas de apoio, e nossos colaboradores defendem e justificam o oferecimento deste modelo de formação. Contudo, o projeto, no decorrer de seu desenvolvimento, enfrentou várias dificuldades. A principal, destacada por vários professores, está na responsabilidade do governo de cumprir sua parte do acordo em relação ao pagamento das bolsas de estudo aos professores leigos. Tais bolsas foram concedidas, segundo o professor Antônio Lino Rodrigues de Sá, somente nas três ou quatro primeiras etapas do curso. Sem os recursos necessários para dar andamento às atividades, o projeto, programado para durar três anos, teve vigência de seis anos. Além disso, observa que além de não pagar as bolsas, o "próprio governo não liberava os professores leigos para irem para as etapas", e muitas vezes também não liberava os polos para que neles acontecessem os cursos. "Não tinha nem local para dar aula", salienta o professor Antônio Lino, e talvez isso justifique a afirmação feita pelo professor Edmir Terra de que alunos e professores nunca sabiam se haveria uma próxima etapa e quando ela aconteceria.

Ao fim e ao cabo, a Secretaria de Educação e o Governo Estadual acabaram não concedendo apoio algum ao projeto. o professor Antônio Carlos Osório destaca que essa falta de apoio se deve à mudança de governo no estado.

A indiferença em relação à formação dos professores no Estado do Mato Grosso do Sul, segundo nossas interpretações, marca, como eixo condutor, a maioria das entrevistas concedidas pelos nossos colaboradores. Em uma delas, por exemplo, o professor Antônio Carlos Osório deixa explícito o desinteresse do governador em relação à formação na Educação
Básica dos jovens no Estado: "Posterior a isso tivemos situações do governo passar, por decreto, o aluno, sem o aluno ter cursado as disciplinas aqui do Estado. Pedro Pedrossian fez isso, aprontou o que pôde".

Todavia, mesmo com todas as dificuldades, com apoio apenas parcial dos professores da própria UFMS, sem apoio do governo e com vários problemas financeiros, o curso encerrouse e, mesmo que em um tempo mais longo do que o previsto, habilitou um número significativo de professores leigos.

[...] as Parceladas, aqui, elas aparecem na fase de consolidação da área inicial, o começo da formação de pós-graduação na área, na formação de grupos de pesquisa na área de Educação Matemática e é isso que considero mudança de paradigma, rompeu com aquela ideologia antiga, porque há espaço para a formação de bacharelado dentro da licenciatura, eu acho que isso deve existir, mas não exclusivamente. (Entrevista do professor Luiz Carlos Pais)

\section{Considerações Finais}

Este texto buscou discutir, exemplificando, um modo de operar com narrativas orais e escritas vinculando dois referenciais teórico-metodológicos distintos: a Hermenêutica de Profundidade e a História Oral. O exemplo dado tem como foco as Licenciaturas em Ciências - habilitação em Matemática - desenvolvidas em regime parcelado no Estado do Mato Grosso do Sul, na década de 1990. Desse modo, tentamos, a partir dos movimentos analíticos da HP e principalmente, mobilizando o conceito de ideologia, que é central à HP, compreender aspectos, de um ponto de vista historiográfico, dessas modalidades emergenciais de formação docente e de seu contexto. Nos foi possível, nessa trama, mobilizar sentidos sobre a organização interna desses cursos, suas características estruturais e as relações entre seus professores, coordenadores e alunos, ressal- 
tando como situações específicas - no caso, os conflitos relativos ao processo de divisão do Estado - deixam marcas nas políticas educacionais. Em um contexto socialmente estruturado, com um Estado recém-criado e castigado por velhos hábitos, os campos de interação, a distribuição de poder, os recursos existentes e as relações sociais constituem-se e se mantêm, criando o solo no qual surgem, na década de 1990, as Licenciaturas de Ciências - Habilitação em Matemática em regime parcelado, caracterizadas pela urgência, pela carência, pela provisoriedade e pelo descompromisso do Estado.

\section{Referências}

ALBUQUERQUE JÚNIOR, D. M. de. História: a arte de inventar o passado - ensaios de teoria da história. Bauru: Edusc, 2007.

ANDRADE, M. M. Ensaios sobre o ensino em geral e o de matemática em particular, de Lacroix: análise de uma forma simbólica à luz do referencial metodológico da hermenêutica de profundidade. 2012. $281 \mathrm{f}$. Tese (Doutorado em Educação Matemática) - Instituto de Geociências e Ciências Exatas, Universidade Estadual Paulista - UNESP, Rio Claro, 2012.

ANDRADE, M. M; OLIVEIRA, F. D. Referencial Metodológico da Hermenêutica de Profundidade na Educação Matemática: reflexões teóricas. In: GARNICA, A. V. M; SALANDIM, M. E. M. Livros, leis, leituras e leitores: exercícios de interpretação para a história da educação matemática. Curitiba: Appris, 2014. p. 17-41.

BAGIO, V. A. Da escrita à implementação das DCE/PR de matemática: um retrato feito a cinco vozes e milhares de mãos. 2014. 350 f. Dissertação (Mestrado em Ciências e em Matemática) - Programa de PósGraduação em Educação em Ciências e em Matemática Universidade Federal do Paraná, Curitiba, 2014.

BITTAR, M. Mato Grosso do Sul, a construção de um estado: regionalismo e divisionismo no sul de Mato Grosso. Campo Grande: Editora UFMS, 2009.
BOLÍVAR, A.; DOMINGOS, J.; FERNÁNDEZ, M. La investigacion biográfico-narrativa en educación: enfoque y metodología. Madrid: Muralla S.A., 2001.

CARDOSO, V. C. A cigarra e a formiga: uma reflexão sobre a educação matemática brasileira da primeira década do século XXI. 2009. 226 f. Tese (Doutorado em Educação) - Faculdade de Educação, Universidade Estadual de Campinas - UNICAMP, Campinas, 2009.

GARNICA, A. V. M.; SOUZA, L. A. D. Elementos de história da educação matemática. São Paulo: Cultura Acadêmica, 2012. (Coleção PROPG Digital).

GARNICA, A. V. M. Uma agenda para a história da educação matemática no Brasil? Revista de História da Educação Matemática, v. 1, n. 1, p. 104-127 2015.

GENETTE, G. Paratextos editoriais. São Paulo: Ateliê Editorial, 2009.

GOMES, M. L. M. Escrita autobiográfica e história da educação matemática. Bolema: Boletim de Educação Matemática, Rio Claro, SP, v. 26, n. 42, p. 105-138, abr. 2012.

GONZALES, K G. Formar professores que ensinam matemática: uma história do movimento das licenciaturas parceladas no Mato Grosso do Sul. 2017. 534 f. Tese (Doutorado em Educação para a Ciência) Faculdade de Ciências, Universidade Estadual Paulista - Unesp, Bauru, 2017.

OLIVEIRA, F. D. Análise de textos didáticos: três estudos. 2008. 222 f. Dissertação (Mestrado em Educação Matemática) -Instituto de Geociências e Ciências Exatas Universidade Estadual Paulista - Unesp, Rio Claro, 2008.

OLIVEIRA, F. D.; ANDRADE, M. M.; SILVA, T. T. P. A hermenêutica de profundidade: possibilidades em educação matemática. Alexandria: Revista de Educação em Ciência e Tecnologia, v. 6, n. 1, p. 119-142, 2013.

PINTO, T. P. Produção de histórias na educação matemática: um exercício com os Projetos Minerva mobilizando texto ficcional e fotografias compósitas. Perspectivas da Educação Matemática, [s. l.], v. 8, número temático, p. 862-881, 2015. 
ROLKOUSKI, E. Vida de professores de matemática: (im)possibilidades de leitura. 2006.298 f. Tese (Doutorado em Educação Matemática) - Instituto de Geociências e Ciências Exatas, Universidade Estadual Paulista - Unesp, Rio Claro, 2006.

RICOEUR, P. Teoria da Interpretação: o discurso e o excesso de significação. Lisboa, Portugal: Edição 70, 1987.

RICOEUR, P. 0 conflito das interpretações: ensaios de hermenêutica. Porto, Brasil: Rés.1988.

SILVA, C. R. M. da. Uma, nove ou dez narrativas sobre as licenciaturas em Ciências e Matemática em Mato Grosso do Sul. 2015. 389 f. Tese (Doutorado em Educação Matemática) - Instituto de Geociências, Universidade Estadual Paulista - Unesp, Rio Claro, 2015.

SILVA, T. T. P. Matrizes e suas cercanias: um estudo histórico a partir de livros didáticos de matemática. Relatório de Iniciação Científica - Departamento de Matemática, Universidade Estadual Paulista Unesp, Bauru, 2010.

THOMPSON, J. B. Ideologia e cultura moderna: teoria social crítica na era dos meios de comunicação de massa. 9. ed. Petrópolis, RJ: Vozes, 2011.

\section{Fontes Orais}

FREITAS, José Luiz Magalhães de. [setembro, 2016]. 21 de setembro de 2016 .

NONATO, Antonio Enes. [novembro, 2013]. Corumbá, MS. 04 de novembro de 2013.

OSÓRIO, Antônio Carlos do Nascimento. [setembro, 2016]. Campo Grande, MS. 24 de setembro de 2016.

PAIS, Luiz Carlos. [fevereiro, 2015]. Campo Grande, MS. 21 de fevereiro de 2015.

SÁ, Antonio Lino Rodrigues de. [março, 2015]. Campo Grande, MS. 06 de março de 2015.

SOUZA, Celso Correia de. [fevereiro, 2015]. Campo Grande, MS. 22 de fevereiro de 2015.

SOUZA, Sidnei Azevedo de. [abril, 2016]. Dourados, MS. 08 de abril de 2016.

TERRA, Edmir Ribeiro. [abril, 2016]. Dourados, MS. 14 de abril de 2016.

Recebido em: 28.12.2018

Aprovado em: 20.03.2019

Kátia Guerchi Gonzales é Doutora em Educação para a Ciência pela UNESP de Bauru. Docente da Universidade Estadual do Mato Grosso do Sul (UEMS - Nova Andradina) e do Programa de Pós-Graduação em Ensino de Ciências e Matemática da Uniderp - Anhanguera. Brasil. e-mail: profkatiaguerchi@gmail.com

R. Walter Hubacher, 138 - Vila Beatriz - Nova Andradina/MS - CEP 79750-000. Telefone: (67) 3925-5188

Antônio Vicente Marafioti Garnica é Doutor em Educação Matemática pela UNESP de Rio Claro, Livre-docente pelo Departamento de Matemática da UNESP de Bauru, docente dos Programas de Pós-Graduação em Educação Matemática (UNESP-Rio Claro) e Educação para a Ciência (UNESP-Bauru).e-mail: vicente.garnica@unesp.br

Av. Eng. Luiz Edmundo Carrijo Coube, 14-01 - Vargem Limpa - Bauru/SP - CEP 17033-360. Telefone: (14) 3103-6000 